
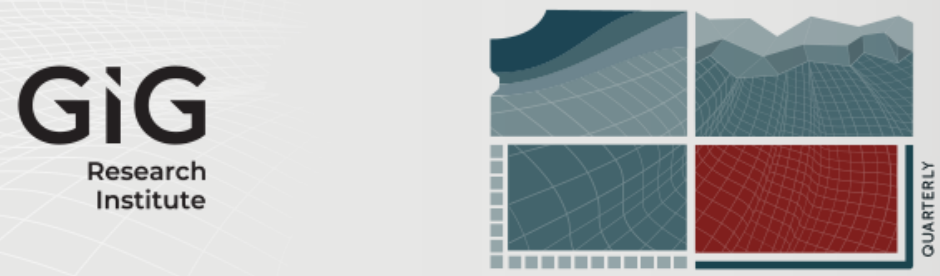

JOURNAL

OF

SUSTAINABLE

MINING

\title{
Study of the relationship of tidal changes in gravity with the time of mining tremors in the area of the mining longwall in a coal mine - case study in USCB, Poland
}

Author(s) ORCID Identifier:

Sławomir Siwek (iD) 0000-0002-3572-9702

Follow this and additional works at: https://jsm.gig.eu/journal-of-sustainable-mining

Part of the Explosives Engineering Commons, Oil, Gas, and Energy Commons, and the Sustainability Commons

\section{Recommended Citation}

Siwek, Sławomir (2021) "Study of the relationship of tidal changes in gravity with the time of mining tremors in the area of the mining longwall in a coal mine - case study in USCB, Poland," Journal of Sustainable Mining: Vol. 20 : Iss. 4 , Article 2.

Available at: https://doi.org/10.46873/2300-3960.1325

This Research Article is brought to you for free and open access by Journal of Sustainable Mining. It has been accepted for inclusion in Journal of Sustainable Mining by an authorized editor of Journal of Sustainable Mining. 


\title{
Study of the relationship of tidal changes in gravity with the time of mining tremors in the area of the mining longwall in a coal mine - case study in USCB, Poland
}

\begin{abstract}
Deep mining of coal deposits in Upper Silesia Coal Basin in Poland over several hundred years has led to disturbances in the natural state of equilibrium. As a result of changes in stress distribution, mass distribution (changes in gravity forces) and deformation of the rock mass, seismic tremors with energy reaching up to $10 \mathrm{E}+09 \mathrm{~J}$ are generated. In this paper, the time of mining tremors occurrence is linked with changes in the gravitational load of the rock mass caused by litosphere tides, which are considered to be one of the factors leading to occurrence of natural seismic tremors. The analysis used data on tremors in the immediate vicinity of the longwall VIII E-E1 in seam 703/1 located in the north-eastern part of the Rydułtowy I mining area, whose mining user is PGG S.A. KWK ROW Rydułtowy. These data was compared with data recorded by gPhoneX-155 tidal gravimeter which measures changes in gravity acceleration. Gravimeter gPhoneX-155 is installed on the stand in the Industrial Cultural Center of Mine Ignacy in Rybnik-Niewiadom, within a few hundred meters of the longwall VIII E-E1. The results obtained in the paper indicate a relationship between changes in gravitational load known as lithosphere tides and the time of longwall mining-induced tremors. At the same time, no periodicity was found in the tremors catalog allowing to link them directly to litosphere tides.
\end{abstract}

\section{Keywords}

earth tides, mining tremors, gravity measurements, tidal gravity meter

\section{Creative Commons License}

\section{(c) (i)}

This work is licensed under a Creative Commons Attribution 4.0 License. 


\title{
Study of the relationship of tidal changes in gravity with the time of mining tremors in the area of the mining longwall in a coal mine - Case study in USCB, Poland
}

\author{
Sławomir Siwek \\ Central Mining Institute (GIG), Plac Gwarków 1, 40-166, Katowice, Poland
}

\begin{abstract}
Deep mining of coal deposits in Upper Silesia Coal Basin in Poland over several hundred years has led to disturbances in the natural state of equilibrium. As a result of changes in stress distribution, mass distribution (changes in gravity forces) and deformation of the rock mass, seismic tremors with energy reaching up to $10 \mathrm{E}+09 \mathrm{~J}$ are generated. In this paper, the time of mining tremors occurrence is linked with changes in the gravitational load of the rock mass caused by lithosphere tides, which are considered to be one of the factors leading to occurrence of natural seismic tremors. The analysis used data on tremors in the immediate vicinity of the longwall VIII E-E1 in seam 703/1 located in the northeastern part of the Rydułtowy I mining area, whose mining user is ROW Mine - Mining Plant Rydułtowy. These data was compared with data recorded by gPhoneX-155 tidal gravimeter which measures changes in gravity acceleration. Gravimeter gPhoneX-155 is installed on the stand in the Industrial Cultural Center of Ignacy Mine in Rybnik-Niewiadom, within a few hundred meters of the longwall VIII E-E1. The results obtained in the paper indicate a relationship between changes in gravitational load known as lithosphere tides and the time of longwall mining-induced tremors. At the same time, no periodicity was found in the tremors catalog allowing to link them directly to lithosphere tides.
\end{abstract}

Keywords: earth tides, mining tremors, gravity measurements, tidal gravity meter

\section{Introduction}

$\mathrm{U}$ nderground hard coal mining with longwall systems in the Upper Silesian Coal Basin in Poland generates a system of forces in Carboniferous rocks that exceed their mechanical strength. When the state of equilibrium is exceeded in the direct vicinity of the exploited longwall, mining tremors are generated [1,2]. Their sources include: cracking of the rock mass connected with compression or tension of the roof rocks, their stratification connected with deflection of the overburden rocks over the selected space, cracks in the rock mass or rockfall [3]. In general, tremors related to relaxation of stresses concentrated in front of the longwall face have a much higher energy than those observed due to deformation of overburden rocks in the process of caving. As a result of the development of seismological observation techniques, computerbased seismic signal processing systems, higher measuring accuracy of the seismometers used and the adjustment of the geometry of their placement around the exploited longwall, catalogs of mining tremors are maintained by mines with increasingly better location of tremor sources and lower thresholds of recorded energies. The basic data contained in each catalog includes the time, place and energy of the source of mining tremors. However, in spite of good surveying of the geological structure and tectonics of the mining area, mechanical properties of rocks and modelling of stress distributions, which makes it possible to determine the area at risk of a tremor, it is still very difficult to determine when such a tremor may occur. 
One of the elements that act as a catalyst for the occurrence of a seismic tremor is considered to be the slow-periodic changes in the gravitational loading of the rock mass resulting from the interaction between the Earth and the surrounding celestial bodies. These interactions are commonly referred to as lithospheric tides. In the world literature it has been proved [4-16], that for appropriately defined catalogs of natural seismic tremors, a relationship between the time function of the tide and the time of occurrence of the seismic tremor is observed. The time function of the tide is usually described by the stress tensor, the vertical tidal acceleration and the rate of change of these factors (derivatives). The catalogs containing seismic tremors of relatively low magnitude in the range 2.0-3.0 are considered as the most likely to be related to tidal influence. Under the conditions of the USCB, this corresponds to mining tremors with energies of the order of $4 \mathrm{E}+05 \mathrm{~J}-4 \mathrm{E}+07 \mathrm{~J}$. At the same time, such tremors occurred at small depths which, for natural seismic tremors originating in contact zones of lithospheric plates or volcanic regions, range from a few to several kilometres. For tremors induced by mining exploitation, these depths range from 0.5 to $3 \mathrm{~km}$ [17].

The aim of this paper is to verify whether it is possible to determine extent slow-variable tidal gravity loads are the direct catalyst for tremors induced by mining longwall exploitation. It can be assumed that such situation occurs when a mining tremor occurs at the moment of maximum or minimum loading of the rock mass caused by tidal changes of gravitational field. In order to achieve the objective of this paper, a set of mining tremors registered at ROW Mine - Mining Plant Rydułtowy during exploitation of the longwall VIII E-E1 in the seam 703/1 has been analysed on the basis of records of tidal gravitational changes registered with the gPhoneX - 155 tidal gravimeter, located at the distance from $1.2 \mathrm{~km}$ to about $200-300 \mathrm{~m}$ from the longwall front. The existence of a periodicity in the sub-catalog of the most energetically strong tremors $(\mathrm{E}+05 \mathrm{~J}-\mathrm{E}+06 \mathrm{~J})$ for periods corresponding to the main lithospheric tidal waves was also investigated.

\section{Observations of tidal changes of gravity}

At the end of 2018, as part of the implementation of the European Plate Observing System - Poland project (acronym EPOS-PL), gPhoneX spring gravimeters with serial numbers 155 and 157 from Micro$\mathrm{g}$ LaCoste Ltd (USA) were purchased at the Central Mining Institute (GIG) in Katowice, Poland. These gravimeters are called tidal gravimeters due to their characteristics allowing continuous observation of changes in the gravity field. This is due to the fact that tidal gravity loads have the greatest influence on the observed daily changes in gravitational field. These changes amount to $300 \mu \mathrm{Gal}$ per day $\left(1 \mu \mathrm{Gal}=10^{-8} \mathrm{~m} / \mathrm{s}^{2}=10 \mathrm{~nm} / \mathrm{s}^{2}\right)$. The main purpose of installing tidal gravimeters at the USCB is to study geodynamic phenomena related to tremors induced in coal mines [18,19]. At the same time, precise observation of tidal gravity effects is carried out (Fig. 1), which after a longer period of observation, stabilisation of instrument drift, will allow verification of gravity coefficients determined theoretically for lithospheric tidal waves [20].

The devices were installed at two stands: at the Upper Silesian Geophysical Observatory (GIG Katowice) - gPhoneX-157 - as a post-mining area where regional seismic tremors are observed and at the Industrial Culture Centre of the Ignacy Mine in Rybnik-Niewiadom - gPhoneX-155 - located in the active mining area of the Rydultowy Mine where mining tremors are observed in the close vicinity of longwalls. So far, there has been no continuous monitoring of changes in the gravity field in relation to the mining exploitation carried out. The installation of gravimeters at such sites should allow for the capture of any differences. Their technical parameters, and site specifications were presented in detail in the publication by [18]. It also presents the observed ability of gravimeters to record mining tremors. The possibility of recording a given mine tremor is strictly dependent on its magnitude (energy) and the distance from the system component (one of the gPhoneX gravimeters). The data obtained indicate that mining tremors of magnitude from about 2.5 to 2.6 have been recorded and have occurred at a distance of up to $20-22 \mathrm{~km}$ from the site.

Determination of the relationship between the Earth's tides and the occurrence of seismic tremors, and in the case of the present paper tremors induced by mining exploitation in the longwall area, can be measured statistically by applying the Schuster test [21]. For this purpose, the first element of the Schuster test was applied, consisting in determining the phase angle of each tremor from the studied catalog with respect to the measured changes in gravity acceleration with the gPhoneX-155 tidal gravimeter. The value of the phase angle is determined in accordance with the work of [4,9], where it was based on the course of the determined tidal stress and the synthetic gravitational effect of the lithosphere tide, respectively. The determination of the phase angles of induced tremors on the summed observed tidal gravitational effect provides fundamental information on the existence of a relationship between the timing of the induced tremor and the change in gravitational loading of the 


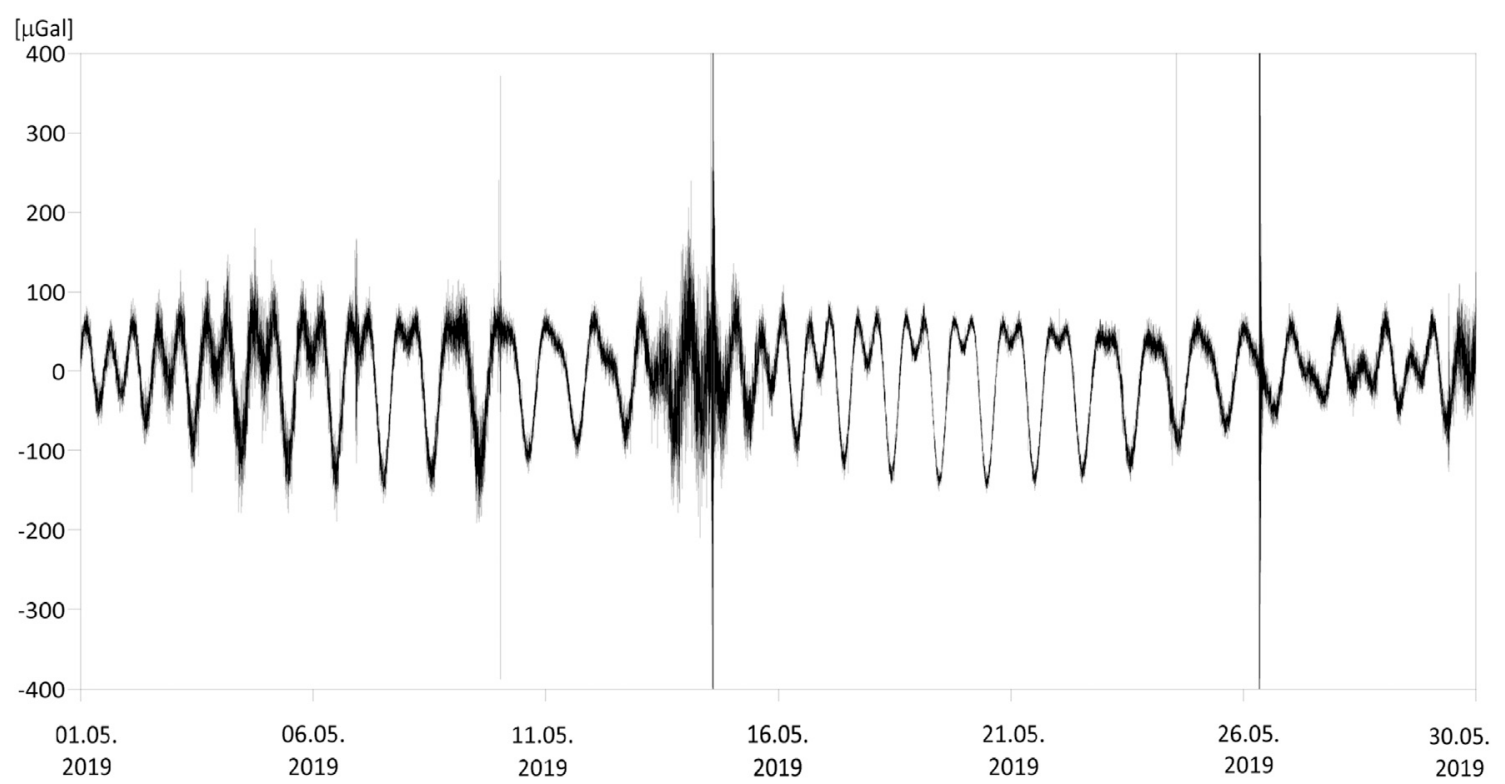

Fig. 1. Observation of changes in gravity acceleration in May 2019 using the gPhoneX-155 tidal gravimeter at the site at ICK ZKI in Rybnik (raw data after subtracting instrumental drift).

rock mass. Since the course of the curve being a total gravitational effect of tidal waves acting on the lithosphere is characterised by large variability (irregular curve), when determining the phase angle of a given tremor each time it was assumed that the maximum and minimum of the curve closest to the tremor are the maximum or minimum loads related to the moment of time when the given tremor occurred (Fig. 2).

The determined phase angle is in the range $\pm 180^{\circ}$, where for an angle of $+180^{\circ}$ and $-180^{\circ}$, therefore it is about tidal gravitational load with maximum

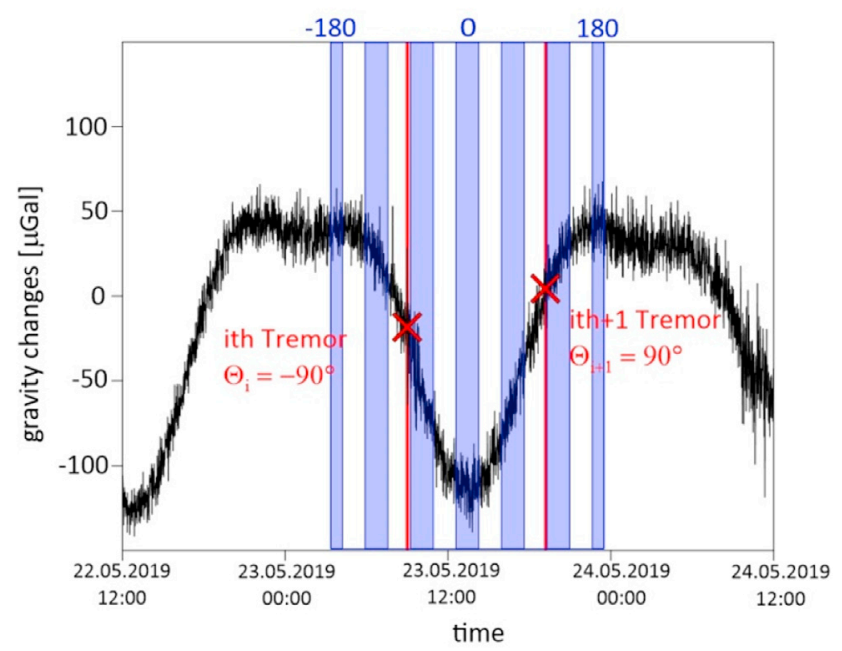

Fig. 2. Definition of the tidal phase angle for variations in gravity acceleration. The maximum and minimum of the tidal gravity change nearest to the seismic tremor are described by $\pm 180^{\circ}$ and $0^{\circ}$ respectively. The phase angle is determined by linearly dividing the time interval between them. amplitude, while for an angle of $0^{\circ}$ it is about maximum relief. Values of $+180^{\circ}$ and $-180^{\circ}$ refer to the same effect of maximum load. The 'minus' sign means that gravitational relief and the 'plus' sign means that the loading. The determination of phase angles is limited to radii of width $30^{\circ}$. Additionally, based on the occurrence times of mining tremors, it is possible to investigate the existence of periodicity in the occurrence of induced tremors using knowledge of the periods of lithospheric tidal waves which causes the highest changes in gravity amplitude [4]. In the Shuster test, each seismic tremor is a unit vector in the direction defined by the phase angle $\Theta_{i}$. Then the vector sum $D$ can be described by the relation:

$D^{2}=\left(\sum_{i=1}^{n} \cos \theta_{i}\right)^{2}+\left(\sum_{i=1}^{n} \sin \theta_{i}\right)^{2}$

where $n$ is the number of seismic tremors in the studied set. When the value $\Theta_{i}$ is determined randomly, then the probability that the length of the vector sum is equal to or greater than $D$ is defined as follows:

$p=e^{\left(-\frac{D^{2}}{n}\right)}$

The probability value determined in the equation is referred to as the $p$-value of the Schuster test. The lower the $p$-value, the higher the probability that the time distribution of tremors depends on the examined period $T$. The value of the $p$-value varies 
from 0 to 1 . When it approaches to 0 , there is a dependence between the tested set of tremors and the tested period. Generally, a threshold of 0.05 $(5 \%)$ is assumed, i.e. probabilities $p<0.05(5 \%)$ are considered as not random and the correlation is considered significant, while $p$-values greater than $5 \%$ correspond to a random event distribution. The socalled Shuster test spectrum [22], in the form of the Schuster spectrum computer script in the MatLab environment [23] was used to investigate the periodicity in the studied catalog of mining tremors. In simple terms, the data of the catalog of seismic tremors (times of tremors) are entered into the script and the boundaries of the examined period are defined, on the basis of which the spectrum of the Schuster test is calculated, i.e. the distribution of the number $p$ with respect to a number of periods contained within the determined boundaries. The script calculates the subsets of periods for which the relationship in the set of tremors will be sought. Detailed elements of how the program works and how to define the settings are included in the paper by [24]. Then, for each of the determined periods, the Shuster test is carried out using an additional script Shuster_test_log on the examined catalog; the natural logarithm of the number $p$ is determined. The results are presented in the form of a logarithmic plot of the $p$-value of the Schuster test for the examined periods, taking into account the threshold for detecting the existence of a dependence $(95 \%)$.

\section{Mining tremors in the area of longwall VIII E-E1}

The Rydułtowy I mining area is formed by Carboniferous formations of the Paralic Series comprising the Poręba Beds (coal beds of the group 600 ) and the Jaklowice Beds (group 700). In the Carboniferous roof, deposits of Upper Silesian sandstone series are also found locally, such as in the case of the hill on which the gPhoneX-155 tidal gravimeter stand is situated in ICK Rybnik (the Głowacki Shaft). Pleistocene sediments of low thickness are deposited directly on Carboniferous formations. In many cases these formations are completely eroded within the elevations of the terrain and their thickness reaches up to $25 \mathrm{~m}$ in the proglacial valleys of water courses (the proglacial valley of the Nacyna River). In the discussed part of the mining area, mining exploitation has been carried out since the end of the 19th century, when coal from the seam 602 was mined at the depth of about 90-100 m below ground level. At present, mining is carried out at a depth of about $1000-1100 \mathrm{~m}$ below ground level.
The analysed set of induced tremors originated from the exploitation of the longwall VIII E-E1 in the seam 703/1, located in the eastern part of the deposit in the mining are Rydułtowy I (Fig. 3). The mining user of this mining are is ROW Mine - Mining Plant Rydułtowy. Longwall VIII E-E1 is adjacent to the boundary pillar of ROW Mine - Mining Plant Marcel, about $100 \mathrm{~m}$ wide, from the west. From the north, it is adjacent to the protective zone of a railway fault, shedding Carboniferous rocks by about $180 \mathrm{~m}$ to the north. To the west of the longwall there are the gobs of the exploited longwall VII E-E1.

The exploitation of longwall VIII-E E1 in seam $703 / 1$, which is the shallowest among coal seams belonging to the Jaklowice Beds, was carried out in varying geological conditions at the depth of about 1000-1100 below ground level. Clay shales (in the roof) and siltstones, and less commonly sandstones (in the floor) are the formations surrounding the deposit. The closest overlying coal seam 630/2, is situated at the depth of about $900 \mathrm{~m}$ (about $100-200 \mathrm{~m}$ shallower). The analysed seam dips to the north-west at angle from $3^{\circ}$ to $10^{\circ}$. The ordinates of the floor in the gallery 8-E-E1 running on the eastern side of the longwall varies from $-741 \mathrm{~m}$ above ground level in the south to $-781 \mathrm{~m}$ above ground level in the north. Running parallel on the western side of the longwall, the 7-E-E1 gallery is located approx. $30 \mathrm{~m}$ lower (from -770 to $810 \mathrm{~m}$ above ground level). The maximum height of the extracted layer was $2.8 \mathrm{~m}$. The average thickness of coal in the excavated layer varied from 1.8 to $2.2 \mathrm{~m}$. In the initial part of the longwall, the coal was separated by a layer of clay shale with a thickness of up to $0.5 \mathrm{~m}$. In the seam, on the side of the 7-E-E1 gallery (western gallery), two small faults were found with a throw ranging from $\mathrm{h}=0.7 \mathrm{~m}$ to $\mathrm{h}=1.2 \mathrm{~m}$, which did not continue in the longwall. The longwall advance was from north to south.

The catalog contains basic data on seismic tremors related to the exploitation of longwall VIII E-E1, which occurred in the period from the commissioning of the longwall on Feb 26th, 2019 to Jan 29th, 2020 (and thus about a month after the termination of its operation on Dec 31st, 2019). The spatial distribution of tremors in relation to the exploited longwall and the measuring stand of the gPhoneX155 gravimeter is illustrated in Fig. 3. In general, tremors are concentrated along the western edge of the exploited longwall, especially in the southwestern corner located at the end of the longwall run in contact with the gobs of the previously exploited longwall VII E-E1. Some tremors also occurred in the pillar from the Marcel hard coal mine. This mainly concerns tremors which occurred 


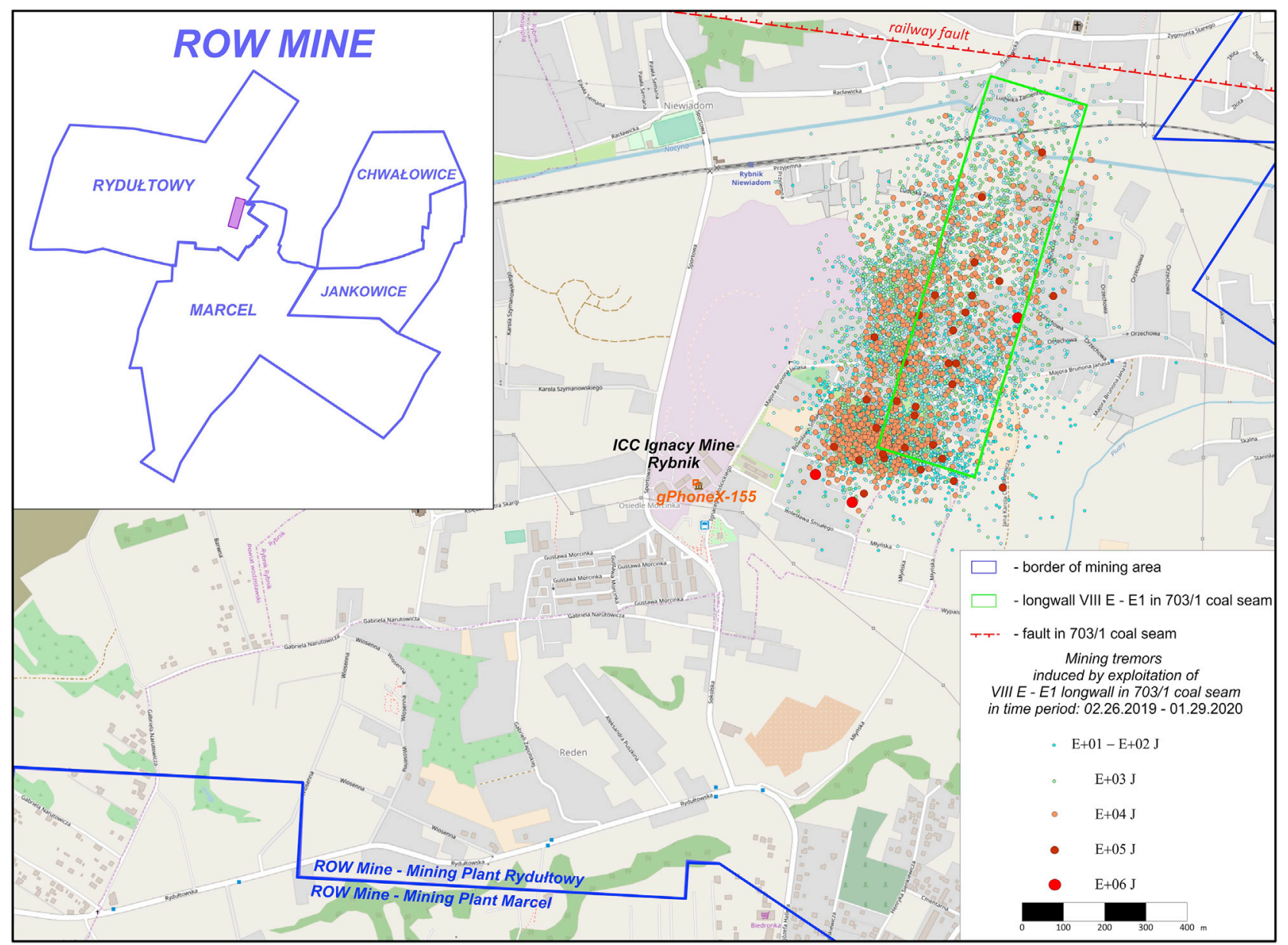

Fig. 3. Location of seismic tremors induced by exploitation of longwall VIIIE-E1 in deposit 703/1 in ROW Mine - Mining Plant Ryduttowy in the period from Feb 26th, 2019 (commissioning of the longwall) to Jan 29th, 2020 (approx. 30 days after completion of the longwall).

before the front of the exploited longwall. Tremors before the front of the exploited longwall make up $85.5 \%$ of the whole catalog. 1033 tremors $(14.5 \%)$ occurred in the rock mass behind the exploitation front of the longwall. At the same time, $98.9 \%$ of tremors from the whole catalog occurred in the seam roof, $94 \%$ of which occurred in sandstones of Poreba Beds lying at the depth of -500 to $-600 \mathrm{~m}$ below sea level. Five tremors occurred at depths corresponding to the position of seam VIII E-1E, and they were the result of de-stress blasting. 75 tremors occurred in the bottom of the seam. The spatial distribution of tremors in the longwall vicinity is illustrated in Fig. 4.

The catalog contains tremors with energies from $4.23 \mathrm{~J}$ to $6.4 \mathrm{E}+06 \mathrm{~J}$, which corresponds to local magnitudes from about 0.05 to about 2.65. The total energy of these tremors was $6.61 \mathrm{E}+07 \mathrm{~J}$. In the catalog containing 7101 tremors registered in the longwall area, only 27 tremors had an energy higher than $3 \mathrm{E}+05 \mathrm{~J}(\mathrm{ML}=2.0)$. Thus, only the tremors have the energy corresponding to natural tremors analysed in the literature. The set is dominated by the weakest tremors with energy $\mathrm{E}+01 \mathrm{~J}-\mathrm{E}+02 \mathrm{~J}$, which constitute almost $62 \%$ of tremors (table on Fig. 5).

The analysed set covers a period of 337 days, and the number of registered tremors is related to the progress of mining and the location of the longwall face (Fig. 5). With the increase in time, the number of tremors recorded on a monthly basis increases. The highest number of them was registered in November 2019, when the location of the mining front corresponded to approximately $80 \%$ of the longwall run, at the same time with a high daily progress of the front of approximately $3.3 \mathrm{mb}$ per day (the average progress for the whole longwall was approximately $2.2 \mathrm{mb} /$ day). The increase in the number of all registered tremors is accompanied by the increase in the number of the strongest tremors, i.e. tremors with the energy of E+05J and E+06J, which constitute the greatest potential threat of rock burst. 


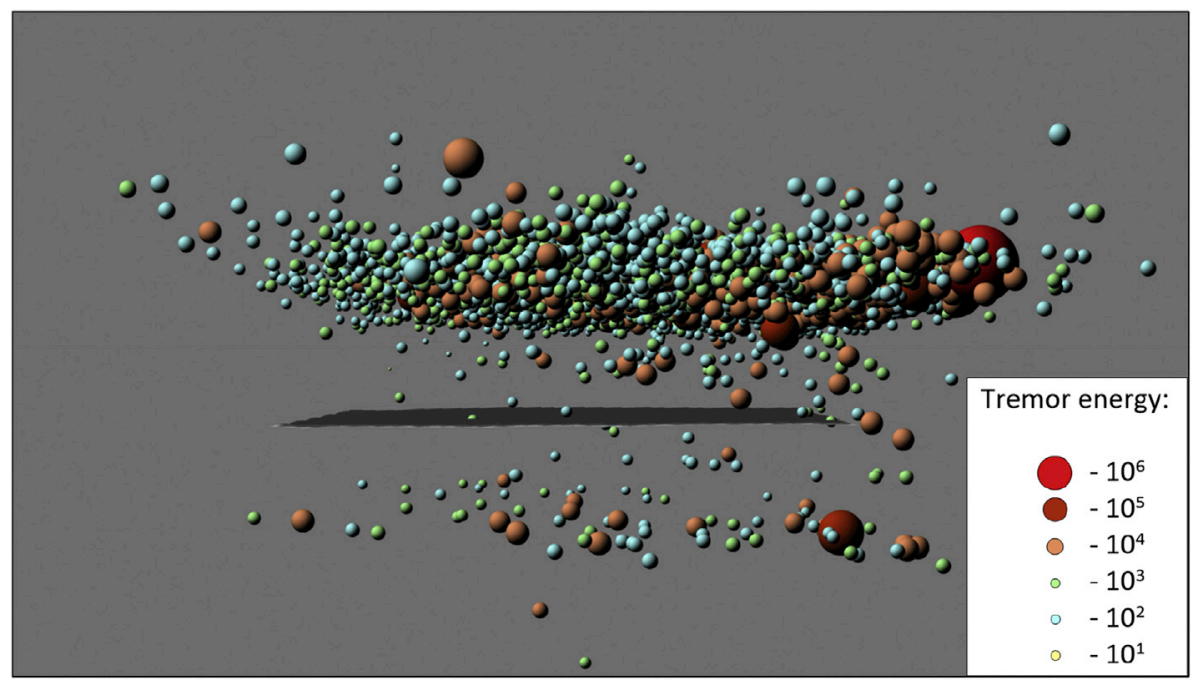

Fig. 4. 3D visualisation of tremors induced by exploitation of longwall VIII E-1E in deposit 703/1 in coal mine ROW Mine - Mining Plant Ryduttowy. View from the western side. The plane depicts location of exploited seam.

\section{Data analysis}

Times of occurrence of induced seismic tremors were superimposed on obtained real changes of acceleration of gravity (tidal effect) which are visible in raw gravity data obtained from recordings made with the gPhoneX-155 tidal gravimeter at the site in the Industrial Cultural Centre of the Ignacy Mine in Rybnik Niewiadom. The only numerical operation on the data from the tidal gravimeter was the removal of instrumental drift. For the purposes of correct data calibration, the times of occurrence of tremors, given in the catalog of the ROW Mine Mining Plant Rydultowy, in local time, were converted into UTC time. The effect of the performed juxtaposition for the whole set from Feb 26th, 2019 to Jan 29th, 2020 is presented in Fig. 6. Weaker

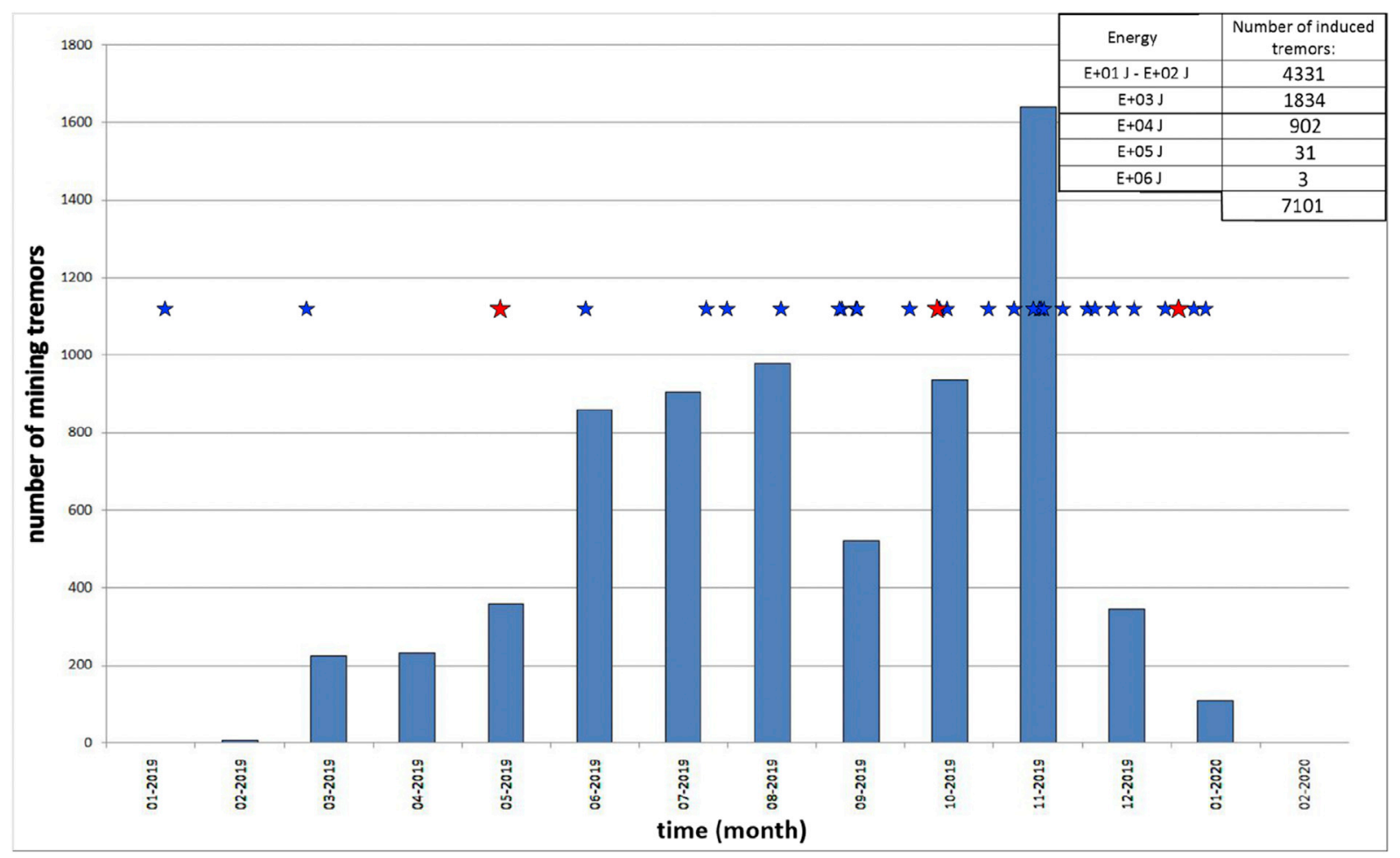

Fig. 5. Distribution of the number of tremors by month for the period Feb 26th,2019-Jan 29th,2020. Blue asterisks indicate tremors with energy E+05J and red asterisks indicate tremors with energy E+06J. 


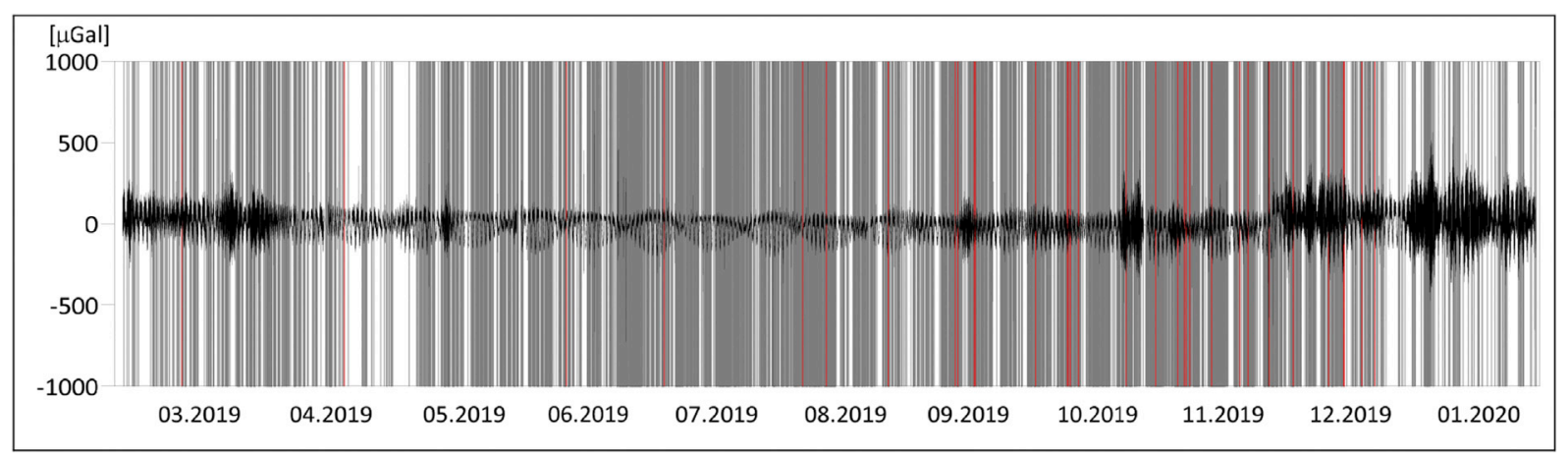

Fig. 6. Distribution of mining tremors recorded during the exploitation of longwall VIII E-E1 in the period Feb 26th, 2019-Jan 28th, 2020 on the actual changes of gravity acceleration (gPhoneX-155).

tremors with energies from $\mathrm{E}+01 \mathrm{~J}$ to $\mathrm{E}+04 \mathrm{~J}$ are marked in grey colour, stronger ones with energies $\mathrm{E}+05 \mathrm{~J}$ and $\mathrm{E}+06 \mathrm{~J}$ in red colour.

For all 7101 tremors their phase angles $\Theta$ have been determined according to the scheme presented in Fig. 2. A combination of 6997 out of 7101 tremors that occurred during the exploitation of the longwall VIII E-E1 has been interpreted (Table 1). No phase angle has been determined for 104 tremors due to the fact that during their occurrence the gravimeter gPhoneX-155 did not register changes in gravity acceleration (breaks in work).

The data in Table 1 are graphically presented in Fig. 7. The whole set (Fig. 7a) is characterized by the fact that almost $27 \%$ of tremors occurred at the time of maximum loading or unloading of the rock mass. Tremors at the time of maximum loading $\left( \pm 180^{\circ}\right)$ accounted for $14.06 \%$ of all tremors, while tremors at the time of maximum unloading $\left(0^{\circ}\right)-12.78 \%$. The strongest tremors, with energies $\mathrm{E}+05 \mathrm{~J}$ and $\mathrm{E}+06 \mathrm{~J}$ (Fig. 7b), occurred especially at maximum loading and gradual unloading of rock mass (phase angle values $180^{\circ}>\Theta>-60^{\circ}$ ), which constitutes $62 \%$ of tremors in this subset. The most numerous subset of tremors are those with energy $\mathrm{E}+01 \mathrm{~J}-\mathrm{E}+02 \mathrm{~J}-4331$ tremors - which constitutes almost $62 \%$ of the whole catalog and thus significantly influences the overall distribution of the catalog.

The obtained correlation between the time of occurrence of mining tremors produced during the exploitation of longwalls and the change of gravitational load of the rock mass indicates that for about $27 \%$ of tremors such a correlation exists. The study of periodicity was carried out with the use of the Schuster test spectrum. As a result of the test, one obtains the graph of logarithm of the number $p$ against the periods for which the test was carried out (Fig. 8).

The values obtained for the sub-catalog covering tremors with energies $\mathrm{E}+05 \mathrm{~J}$ and $\mathrm{E}+06 \mathrm{~J}$ (i.e. tremors that energetically correspond to natural tremors analysed in the world literature), the value of logarithm of the Schuster p-number for periods corresponding to the main 20 lithospheric tidal waves (vertical dashed blue lines) show no relationship between the tidal wave periods studied and the time of occurrence of these strongest tremors.

Similarly, the other groups of tremors $(\mathrm{E}+01 \mathrm{~J}-\mathrm{E}+02 \mathrm{~J}, \mathrm{E}+03 \mathrm{~J}, \mathrm{E}+04 \mathrm{~J})$ are characterized by lower energy but high number of tremors. In the world literature, in the analysis of tidal linkages, groups of low-energy tremors are usually treated as the so-called 'swarms of tremors' or tremors accompanying strong earthquakes and in the analysis they are treated as a single event with averaged energy and time of occurrence. The performed analysis and obtained spectra of the Schuster test for groups of tremors $\mathrm{E}+01 \mathrm{~J}-\mathrm{E}+04 \mathrm{~J}$ are burdened with a large error. This indicates that

Table 1. Comparison of determined phase angles of time of occurrence of a mining tremor during exploitation of the longwall VIII E-E1 in relation to the actual changes in acceleration of gravity caused by tides in the lithosphere.

\begin{tabular}{|c|c|c|c|c|c|c|c|c|c|c|c|c|}
\hline$\Theta$ & \pm 180 & -150 & -120 & -90 & -60 & -30 & 0 & 30 & 60 & 90 & 120 & 150 \\
\hline$N_{E+01-E+06}$ & 984 & 418 & 479 & 460 & 559 & 552 & 894 & 504 & 616 & 542 & 585 & 434 \\
\hline$N_{E+01-E+02}$ & 591 & 263 & 306 & 277 & 346 & 302 & 557 & 301 & 369 & 314 & 372 & 273 \\
\hline$N_{E+03}$ & 259 & 102 & 119 & 120 & 147 & 155 & 213 & 131 & 160 & 142 & 152 & 106 \\
\hline$N_{E+04}$ & 129 & 49 & 51 & 59 & 62 & 65 & 122 & 70 & 84 & 85 & 58 & 53 \\
\hline$N_{E+05-E+06}$ & 5 & 4 & 3 & 5 & 4 & 0 & 2 & 2 & 3 & 1 & 3 & 2 \\
\hline
\end{tabular}




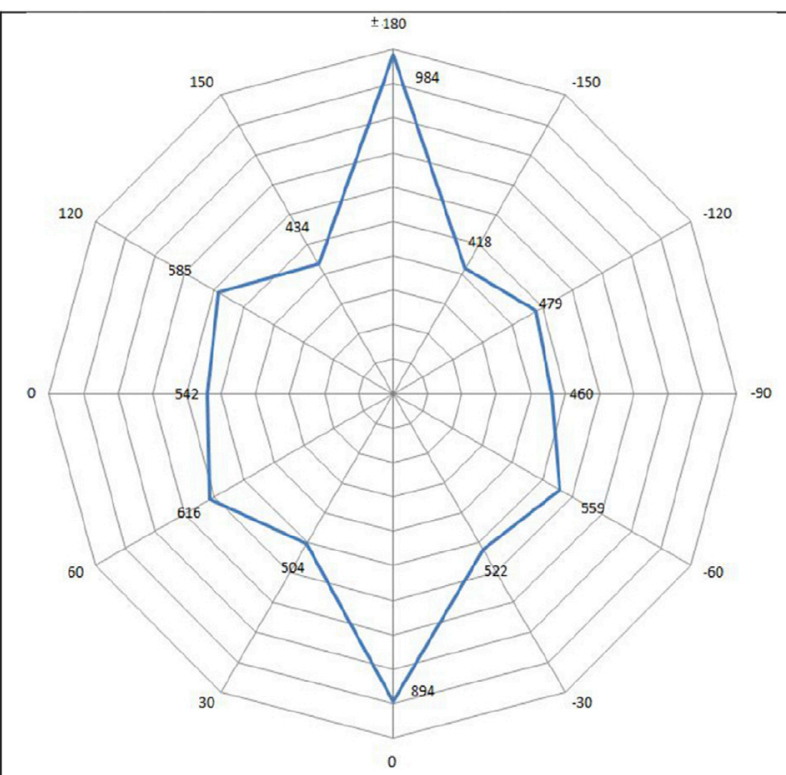

a)

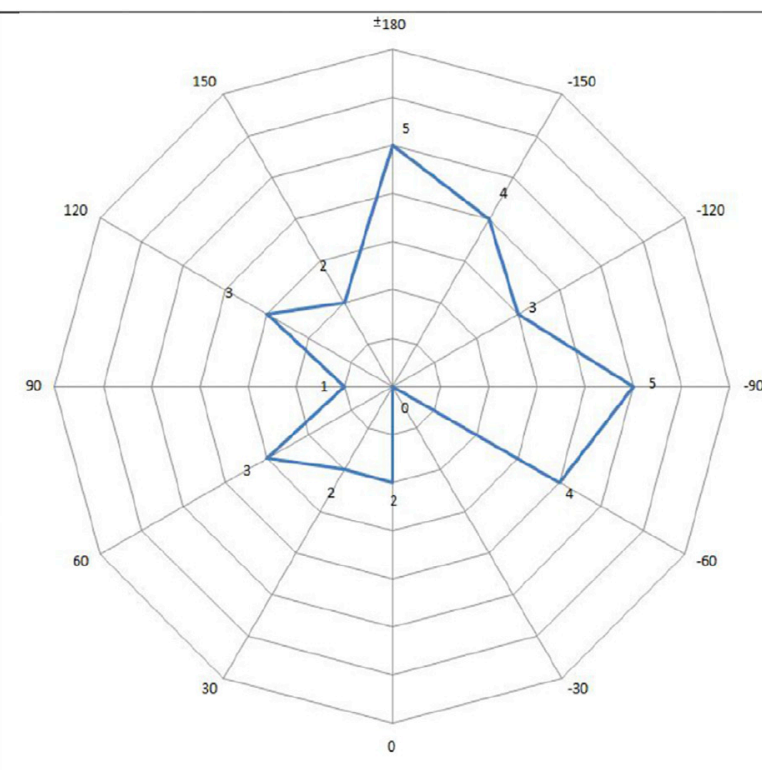

b)

Fig. 7. Distribution of tremors induced by the exploitation of the longwall VIII E-E1 on the basis of the determined phase angle in relation to the total real changes of acceleration of gravity caused by the lithosphere tide. a) for the whole set of tremors $E+01-E+06 J$; $b$ ) for the summed tremors $E+05-E+06 J$.

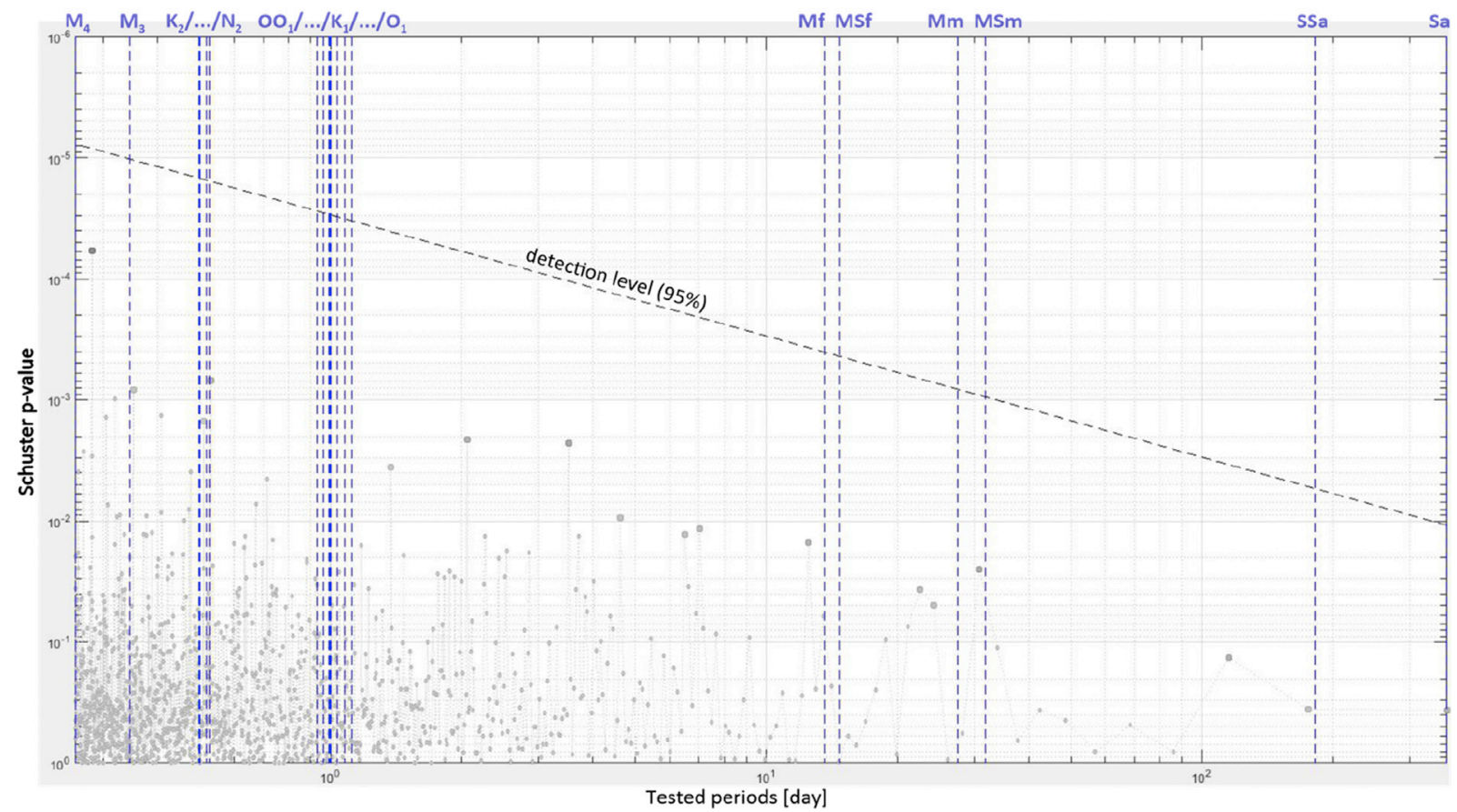

Fig. 8. Shuster spectrum for the catalog of tremors with E+05J and E+06J that occurred between Feb 26th, 2019 to Jan 29 th, 2020.

weaker tremors registered during the exploitation of the longwall VIII E-E1 in the seam 703/1 result directly from the deformation of rocks due to the mining exploitation.

\section{Conclusions}

Following the launch of the European Plate Observing System - Poland project (acronym EPOS-PL) in the Upper Silesian region, continuous 
measurements of changes in gravity acceleration via tidal gravimeters have become possible. These refers to changes in the short term, caused by nearby mining tremors or distant strong earthquakes, and in the long term, caused by the gravitational interaction of the celestial bodies of the solar system with the Earth, commonly referred to as tides. In this paper, changes in gravity acceleration registered continuously by the gPhoneX-155 tidal gravimeter have been related to the time of occurrence of seismic tremors induced by exploitation of the longwall VIII E-E1 in the seam 703/1 in the ROW Mine - Mining Plant Rydultowy. As a result of applying an element of one of the most common tools of harmonic analysis - the Schuster test, results were obtained indicating that for about $27 \%$ of mine tremors induced by longwall exploitation, the time of their occurrence took place at the moment of maximum stress or gravitational relief of the rock mass. This may indicate that small changes of stress in the rock mass in the nearequilibrium state, caused by gravitational forces, may be a catalyst for the occurrence of a mining tremor. The analysis of the existence of periodicity in the catalog of mining tremors and its connection with the periods of the most important lithospheric tidal waves, carried out in accordance with the catalogs of natural tremors, did not show the existence of such connection.

The conducted study indicates that gravitational influence in the form of Earth's tide in the rock mass where underground hard coal mining in the USCB area is carried out, can be a catalyst for the occurrence of mining tremors. The universality of the applied research method allows for the determination of similar relationships for other mineral deposits whose exploitation is accompanied by induced seismicity.

\section{Funding body}

This paper uses data produced in the framework of the project entitled European Plate Observation System, with acronym EPOS-PL, financed within the framework of measure 4.2 of the Intelligent Development Programme, co-financed by the European Union from the European Regional Development Fund (ERDF). Project number: POIR.04.02.00-14-A003/16-00.

\section{Conflicts of interest}

None declared.

\section{Ethical statement}

The author states that the research was conducted according to ethical standards.

\section{References}

[1] Gibowicz S. Mechanizm ognisk wstrząsów górniczych. Publikacje IGFPAN, M-13 (221). PWN Warszawa; 1989.

[2] Zuberek WM, Teper L, Idziak AF, Sagan G. Tectonophysical approach to the description of mining induced seismicity in the Upper Silesia $\mathrm{w}$ Tectonophysics in Minig Areas pod red. Idziak A. wyd. Uniwersytet Sląski Katowice. 1996. p. 78-98.

[3] Marcak H, Zuberek W. Geofizyka górnicza. Katowice: Śląskie Wydawnictwo Techniczne; 1994. p. 110-65.

[4] Tanaka S, Ohtake M, Sato H. Evidence for tidal triggering of earthquakes as revealed from statistical analysis of global data. J Geophys Res 2002a;107(B10):2211.

[5] Tanaka S, Ohtake M, Sato H. Spatio-temporal variation of the tidal triggering effect on earthquake occurrence associated with the 1982 South Tonga earthquake of Mw 7.5. Geophys Res Lett 2002b;29(16). https://doi.org/10.1029/2002GL015386.

[6] Tanaka S, Ohtake M, Sato H. Tidal triggering of earthquakes on Japan related to the regional tectonic stress. Earth Planet Space 2004;56:511-5.

[7] Tanaka S. Tidal triggering of earthquakes precursory to the $2004 \mathrm{Mw}=9.0$ off Sumatra earthquake. In: the 4th international workshop on statistical seismology; 2005.

[8] Tanaka S. Tidal triggering of earthquakes prior to the 2011 Tohoku-Oki earthquake $\left(\mathrm{M}_{\mathrm{w}}\right.$ 9.1). Geophys Res Lett 2012;39: L00G26. https://doi.org/10.1029/2012GL051179.

[9] Cadicheanu N, van Ruymbeke M, Zhu P. Tidal triggering evidence of intermediate depth earthquakes in the Vrancea zone (Romania). Nat Hazards Earth Syst Sci 2007;7:733-40.

[10] Metivier L, de Viron O, Conrad CP, Reanult S, Diament M, Patau G. Evidence of earthquake triggering by the solid Earth tides. Earth Planet Sci Lett 2009;278:370-5.

[11] Kolvankar VG, More S, Thakur N. Earth tides and earthquakes. New Conc Glob Tect Newslett 2010;(57):54-84.

[12] Kolvankar VG. Sun, moon and earthquakes. New Conc Glob Tect Newslett 2011;(60):50-66.

[13] Iwata T. Earthquake triggering caused by the external oscillation od stress/strain changes. In: Community online resource for statistical seismicity analysis; 2012. https:// doi.org/10.5078/corssa-65828518.

[14] Chen L, Chen JG, Xu QH. Correlation between solid tides and worldwide earthquakes $M_{s} \geq 7.0$ since 1900. Nat Hazards Earth Syst Sci 2012;12:587-90.

[15] Dutilleul P, Johnson CW, Burgmann R, Wan Y, Shen ZK. Mulifrequential periodogram analysis of earthquake occurrence: an alternative approach to the Schuster spectrum, with two example in central California. American Geophysical Union. J Geophys Res: Solid Earth 2015. https:// doi.org/10.1002/2015JB012467.

[16] Moncayo GA, Zuluaga JI, Monsalve G. Correlation between tides and seismicity in Northwestern South America: the case of Colombia. J S Am Earth Sci 2019;89:227-45. https:// doi.org/10.1016/j.jsames.2018.11.020.

[17] Mutke G. Oddziaływanie górniczych wstrząsów sejsmicznych na powierzchnię. Monografia. Wydawnictwo GIG Katowice; 2019. ISBN 978-83-65503-21-3.

[18] Kotyrba A, Frolik A, Kortas Ł, Siwek S. Grawimetrycznohydrometryczny system monitoringu wstrząsów górniczych na Górnym Śląsku. Przegląd Geologiczny, j. polski 2020; 68(11):833-42.

[19] Kotyrba A, Kortas Ł. Co-seismic signals of mining tremors in continuous recordings of gravity by gPhoneX tidal gravimeters. Int J Rock Mech Min Sci 2020;129/104288:1-12. 
[20] Timmen L. Absolute and relative gravimetry - chapter 1 in science of geodesy-I. In: Xu Geochang, editor. Advances and future directions. Springer; 2010. p. 1-44.

[21] Schuster A. On lunar and solar periodicities of earthquakes. Proc Roy Soc Lond 1897;61:455-65.

[22] Ader TJ, Avouac J-P. Detecting periodicities and declustering in earthquake catalogs using the Schuster spectrum, application to Himalayan seismicity. Earth Planet Sci Lett 2013. https://doi.org/10.1016/j.eps1.2013.06.032.

[23] http://www.tectonics.caltech.edu/resources/.

[24] Ader TJ, Avouac J-P. Detecting periodicities in earthquake catalogs using the Schuster test - auxiliary material. Earth Planet Sci Lett 2013. https://doi.org/10.1016/j.epsl.2013.06. 032. 